\title{
Fidelity and Adherence to a Liquefied Petroleum Gas Stove and Fuel Intervention during Gestation: The Multi-Country Household Air Pollution Intervention Network (HAPIN) Randomized Controlled Trial
}

\author{
Ashlinn K. Quinn 1,2,*(D), Kendra N. Williams ${ }^{3,4}{ }^{(\mathbb{D}}$, Lisa M. Thompson ${ }^{5}$ (D) Steven A. Harvey ${ }^{6}$, \\ Ricardo Piedrahita ${ }^{2}{ }^{(D}$, Jiantong Wang ${ }^{7}$, Casey Quinn ${ }^{8}{ }^{\circ}$, Ajay Pillarisetti ${ }^{7}$, , John P. McCracken ${ }^{9,10}$, \\ Joshua P. Rosenthal ${ }^{1}$ (D), Miles A. Kirby ${ }^{11}$, Anaité Diaz Artiga ${ }^{10} \mathbb{D}$, Gurusamy Thangavel ${ }^{12} \mathbb{D}$, \\ Ghislaine Rosa ${ }^{13} \mathbb{D}$, J. Jaime Miranda ${ }^{14,15} \mathbb{D}$, William Checkley ${ }^{3,4,6}$, Jennifer L. Peel ${ }^{16}$ \\ and Thomas F. Clasen ${ }^{7}$ (D) on behalf of HAPIN Investigators
}

check for

Citation: Quinn, A.K.; Williams, K.N.; Thompson, L.M.; Harvey, S.A.; Piedrahita, R.; Wang, J.; Quinn, C.; Pillarisetti, A.; McCracken, J.P.; Rosenthal, J.P.; et al. Fidelity and Adherence to a Liquefied Petroleum Gas Stove and Fuel Intervention during Gestation: The Multi-Country Household Air Pollution Intervention Network (HAPIN) Randomized Controlled Trial. Int. J. Environ. Res. Public Health 2021, 18, 12592. https:// doi.org/10.3390/ijerph182312592

Academic Editor:

Camille Raynes-Greenow

Received: 29 September 2021 Accepted: 17 November 2021 Published: 29 November 2021

Publisher's Note: MDPI stays neutral with regard to jurisdictional claims in published maps and institutional affiliations.

Copyright: (C) 2021 by the authors. Licensee MDPI, Basel, Switzerland. This article is an open access article distributed under the terms and conditions of the Creative Commons Attribution (CC BY) license (https:/ / creativecommons.org/licenses/by/ $4.0 /)$.
1 Fogarty International Center, National Institutes of Health, Bethesda, MD 20892, USA; joshua.rosenthal@.nih.gov

2 Berkeley Air Monitoring Group, Fort Collins, CO 80524, USA; rpiedrahita@berkeleyair.com

3 Division of Pulmonary and Critical Care, School of Medicine, Johns Hopkins University, Baltimore, MD 21287, USA; kendra.williams@jhu.edu (K.N.W.); wcheckl1@jhmi.edu (W.C.)

4 Center for Global Non-Communicable Disease Research and Training, Johns Hopkins University, Baltimore, MD 21287, USA

5 Nell Hodgson Woodruff School of Nursing, Emory University, Atlanta, GA 30322, USA; lisa.thompson@emory.edu

6 Department of International Health, Johns Hopkins Bloomberg School of Public Health, Baltimore, MD 21205, USA; Steven.Harvey@jhu.edu

7 Rollins School of Public Health, Emory University, Atlanta, GA 30322, USA; jiantong.wang@emory.edu (J.W.); ajay.p@emory.edu (A.P.); thomas.f.clasen@emory.edu (T.F.C.)

8 Department of Mechanical Engineering, Colorado State University, Fort Collins, CO 80523, USA; Casey.Quinn@colostate.edu

9 Department of Epidemiology and Biostatistics, Global Health Institute, College of Public Health, University of Georgia, Athens, GA 30606, USA; John.McCracken@uga.edu

10 Center for Health Studies, Universidad del Valle de Guatemala, Guatemala City 01015, Guatemala; adiaz@ces.uvg.edu.gt

11 Department of Global Health and Population, Harvard T.H. Chan School of Public Health, Boston, MA 02115, USA; mkirby@hsph.harvard.edu

12 Department of Environmental Health Engineering, Faculty of Public Health, Sri Ramachandra Institute for Higher Education and Research, Porur, Chennai 600116, India; thangavel@ehe.org.in

13 Faculty of Infectious and Tropical Diseases, London School of Hygiene and Tropical Medicine, London WC1E 7HT, UK; Ghislaine.Rosa@lshtm.ac.uk

14 Department of Medicine, School of Medicine, Universidad Peruana Cayetano Heredia, Lima 15102, Peru; jaime.miranda@upch.pe

15 CRONICAS Center of Excellence in Chronic Diseases, Universidad Peruana Cayetano Heredia, Lima 15074, Peru

16 Department of Environmental \& Radiological Health Sciences, Colorado State University, Fort Collins, CO 80523, USA; Jennifer.Peel@colostate.edu

* Correspondence: aquinn@berkeleyair.com

Abstract: Background: Clean cookstove interventions can theoretically reduce exposure to household air pollution and benefit health, but this requires near-exclusive use of these types of stoves with the simultaneous disuse of traditional stoves. Previous cookstove trials have reported low adoption of new stoves and/or extensive continued traditional stove use. Methods: The Household Air Pollution Intervention Network (HAPIN) trial randomized 3195 pregnant women in Guatemala, India, Peru, and Rwanda to either a liquefied petroleum gas (LPG) stove and fuel intervention $(n=1590)$ or to a control $(n=1605)$. The intervention consisted of an LPG stove and two initial cylinders of LPG, free fuel refills delivered to the home, and regular behavioral messaging. We assessed intervention fidelity (delivery of the intervention as intended) and adherence (intervention use) through to the end of gestation, as relevant to the first primary health outcome of the trial: infant birth weight. Fidelity and 
adherence were evaluated using stove and fuel delivery records, questionnaires, visual observations, and temperature-logging stove use monitors (SUMs). Results: 1585 women received the intervention at a median (interquartile range) of 8.0 (5.0-15.0) days post-randomization and had a gestational age of 17.9 (15.4-20.6) weeks. Over 96\% reported cooking exclusively with LPG at two follow-up visits during pregnancy. Less than $4 \%$ reported ever running out of LPG. Complete abandonment of traditional stove cooking was observed in over $67 \%$ of the intervention households. Of the intervention households, $31.4 \%$ removed their traditional stoves upon receipt of the intervention; among those who retained traditional stoves, the majority did not use them: traditional stove use was detected via SUMs on a median (interquartile range) of $0.0 \%(0.0 \%, 1.6 \%)$ of follow-up days (median follow-up = 134 days). Conclusions: The fidelity of the HAPIN intervention, as measured by stove installation, timely ongoing fuel deliveries, and behavioral reinforcement as needed, was high. Exclusive use of the intervention during pregnancy was also high.

Keywords: cookstoves; LPG; randomized controlled trial; adherence; fidelity; intervention

\section{Introduction}

Household air pollution (HAP) is one of the most ubiquitous environmental exposures worldwide, particularly in resource-poor settings. HAP is responsible for 2.3 million deaths and 91 million disability-adjusted life years lost each year [1]. Throughout the last decade, many interventions have attempted to mitigate HAP through cleaner biomass-burning stoves or cleaner energy interventions [2-5]; however, most intervention trials have failed to achieve clean air quality targets until recently [6]. Proposed reasons for failure include the continued mixed use of traditional and intervention stoves ("stove stacking", [2,7]) and the infiltration of outdoor air pollution [8]. In HAP trials, as in other implementation trials, fidelity (the extent to which an intervention was delivered as intended $[9,10]$ ) and adherence (the extent to which it was adopted by participants) are therefore necessary components of trial evaluation that can identify contextual factors that may underlie effectiveness [11].

The Household Air Pollution Intervention Network (HAPIN) trial is a multi-country randomized controlled trial (RCT) of a liquefied petroleum gas (LPG) stove and fuel intervention, complemented with behavioral support, aimed at improving health outcomes among 3195 pregnant women in four countries [12]. Following intervention at between 9 and 20 weeks' gestation, we are following participants for approximately 5-7 months in pregnancy and an additional 12 months following birth. As of September 2020, all HAPIN births had occurred; the analysis of the first primary outcome, infant birth weight, is underway. Additional primary outcomes to be evaluated after an additional year of follow-up include stunting, severe pneumonia in children under one, and blood pressure in older adult women (Figure 1).

As models suggest that even the occasional use of traditional stoves can lead to exposures above health-relevant guidelines [13], the HAPIN trial was designed to enable and motivate participating households to use their LPG stoves for all their cooking needs, while simultaneously, through the use of behavioral change approaches, urging them to discontinue use of their traditional stoves. To this end, the development of tailored behavioral and stove use reinforcement messages and related media supporting the use of the LPG stove in each research setting was integrated into the intervention and has been described previously [14]. This effort sought to reduce the continued use of traditional stoves to the absolute minimum in intervention homes and to discourage the practice of stove stacking. 


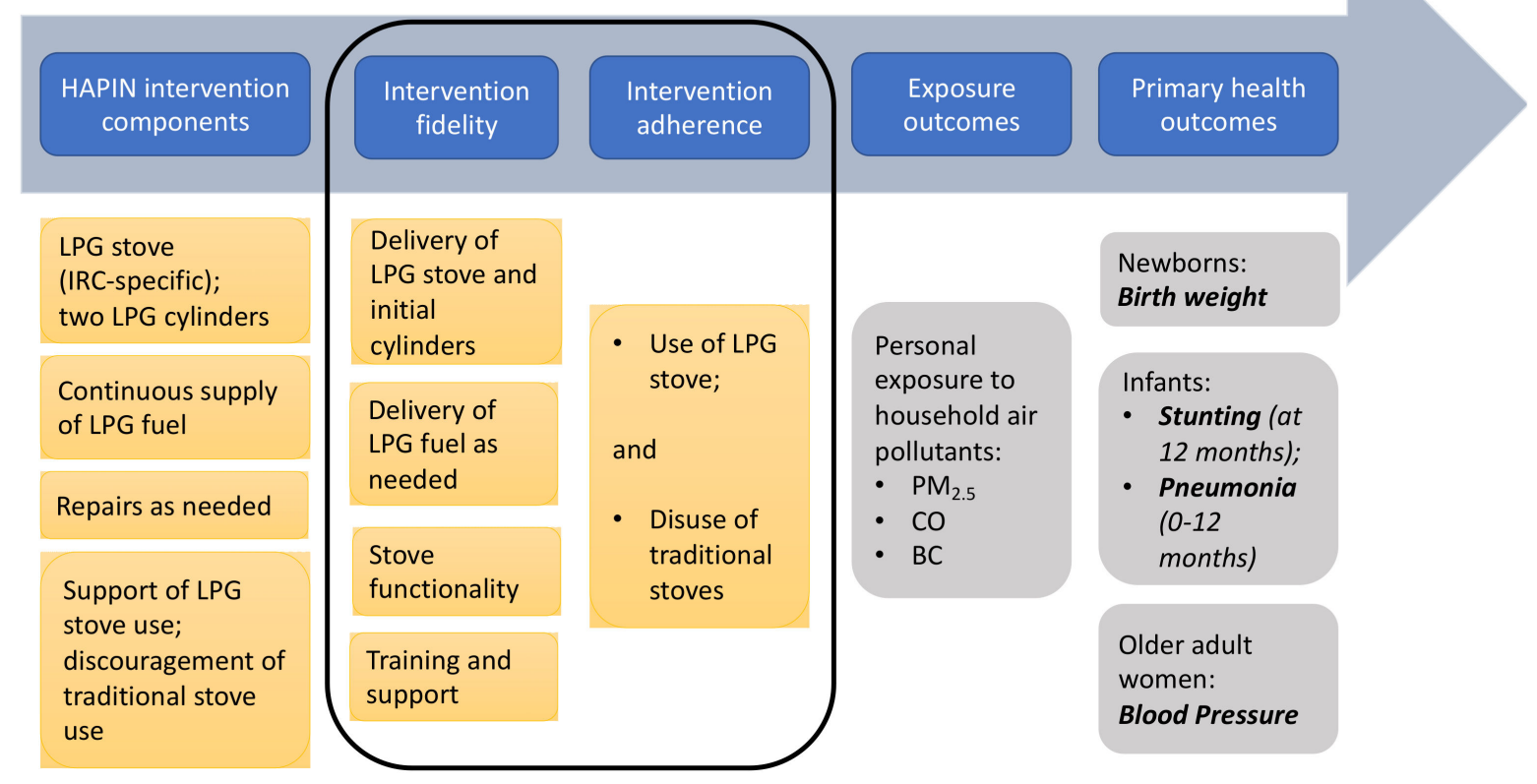

Figure 1. Environmental health theory of change for HAPIN intervention. HAPIN theory of change, outlining intervention components and metrics of fidelity and adherence thought to underlie exposure and primary health outcomes. Yellow boxes represent aspects of the HAPIN trial under investigation in this paper, for the period from enrollment through to the end of gestation (relevant to the first primary outcome: newborn birth weight). Grey boxes represent outcomes further on the change pathway (not reported here). The black outline encircles this manuscript's areas of focus. $\mathrm{PM}_{2.5}$, particulate matter less than $2.5 \mu \mathrm{m}$ in diameter. $\mathrm{CO}$, carbon monoxide. $\mathrm{BC}$, black carbon.

Here, we report metrics related to intervention fidelity (stove and fuel delivery in addition to behavioral support) and adherence (stove usage patterns) from intervention through to the first primary endpoint: infant birth weight. The time period of interest here is the period between trial enrollment and the end of the gestation, defined by a live birth, a stillbirth, or study withdrawal prior to birth. Our goal is to understand whether the intervention as delivered was effective in achieving the exclusivity of LPG use during this period, and to report on these key aspects of the intervention process before the main trial outcome (impact on infant birth weight) is known. A similar analysis of intervention fidelity and adherence for the one-year period following birth (relevant to downstream health outcomes) will be conducted at the conclusion of the trial.

\section{Methods}

The design of this evaluation largely followed the recommendations for process evaluation discussed by Moore et al. These include: clarification of the causal assumptions of the intervention, identification of key questions and methods that would shed light on these assumptions, and analysis and reporting of fidelity and adherence data before trial outcomes are known, to avoid potential biases in interpretation [11].

The theory of change underlying the intervention's desired effect on health outcomes was outlined by the principal investigators and members of the HAPIN Behavioral and Economics Core (Figure 1). Within it, questions related to intervention fidelity and adherence are assumed to be necessary prerequisites to the reductions in exposure that are hypothesized to lead causally to the desired health outcomes, including increased infant birth weight. 


\subsection{Trial Setting}

Our trial has been described previously $[12,15,16]$. We enrolled a total of 3195 pregnant women —approximately 800 in each of four international research centers (IRCs) - in Jalapa, Guatemala; Puno, Peru; Kayonza, Rwanda; and Tamil Nadu, India (Table 1). Gestational age (of 9 to 20 weeks' gestation per the trial's eligibility requirements) was determined via ultrasound, and half of the participants were randomized to receive an intervention consisting of a liquefied petroleum gas (LPG) stove, free LPG fuel delivered as needed, free stove repairs, and behavioral reinforcement to support exclusive LPG stove use. Control participants continued using their own (primarily traditional, biomass-burning) stoves for their cooking needs, and are to be compensated for their participation either with an LPG stove at the end of the trial or with other items of their choosing [17].

Table 1. Participants in HAPIN throughout gestation.

\begin{tabular}{|c|c|c|c|c|c|c|c|c|c|}
\hline \multirow{2}{*}{$\begin{array}{l}\text { Treatment Group } \\
\text { IRC }\end{array}$} & \multicolumn{4}{|c|}{ Control } & \multicolumn{4}{|c|}{ Intervention } & \multirow[t]{2}{*}{ Total } \\
\hline & Guatemala & India & Peru & Rwanda & Guatemala & India & Peru & Rwanda & \\
\hline Enrolled women $(\mathrm{N})$ & 400 & 399 & 402 & 404 & 400 & 400 & 396 & 394 & 3195 \\
\hline Exits before birth $(\mathrm{N})$ & 14 & 13 & 44 & 10 & 16 & 12 & 11 & 15 & 135 \\
\hline Live births $(\mathrm{N})$ & 386 & 386 & 358 & 394 & 384 & 388 & 385 & 379 & 3060 \\
\hline $\begin{array}{l}\text { Days in study during pregnancy } \\
\text { (randomization to the end of } \\
\text { gestation): median (Q1, Q3) }\end{array}$ & $\begin{array}{l}164.0 \\
(144.8 \\
181.0) \\
\end{array}$ & $\begin{array}{l}156.0 \\
(136.5 \\
172.5) \\
\end{array}$ & $\begin{array}{l}160.0 \\
(136.0 \\
180.0) \\
\end{array}$ & $\begin{array}{l}171.0 \\
(154.0 \\
185.0) \\
\end{array}$ & $\begin{array}{l}162.0 \\
(143.0 \\
178.0)\end{array}$ & $\begin{array}{l}155.0 \\
(136.0 \\
171.0)\end{array}$ & $\begin{array}{l}158.0 \\
(138.0 \\
180.0) \\
\end{array}$ & $\begin{array}{l}166.0 \\
(152.0 \\
182.0)\end{array}$ & $\begin{array}{l}162.0 \\
(142.0 \\
179.0)\end{array}$ \\
\hline Household size: median (Q1, Q3) & $\begin{array}{c}4 \\
(3,6) \\
\end{array}$ & $\begin{array}{c}3 \\
(3,5) \\
\end{array}$ & $\begin{array}{c}4 \\
(3,6) \\
\end{array}$ & $\begin{array}{c}3 \\
(3,4) \\
\end{array}$ & $\begin{array}{c}5 \\
(3,7) \\
\end{array}$ & $\begin{array}{c}3.5 \\
(3,5) \\
\end{array}$ & $\begin{array}{c}4 \\
(3,5) \\
\end{array}$ & $\begin{array}{c}3 \\
(2,4) \\
\end{array}$ & $\begin{array}{c}4 \\
(3,5) \\
\end{array}$ \\
\hline
\end{tabular}

\subsection{Intervention Design}

LPG stoves and fuel cylinders were different in each research setting, according to local supply and cooking habits, and informed by formative research on cooking practices in each community [14,18]. Each LPG stove had at least two burners; stoves in Guatemala, Peru, and Rwanda had three burners. The stove in Guatemala incorporated a flat griddle or "comal" for cooking tortillas (a staple food in the region), while households in Rwanda were supplied with an add-on roasting device to prepare roasted meats. We developed partnerships with local LPG distributors to supply LPG during the trial. LPG cylinder sizes were locally specific (containing, in Guatemala, $11.3 \mathrm{~kg}$ of LPG; India, $14.2 \mathrm{~kg}$; Peru, $10 \mathrm{~kg}$; and Rwanda, $15 \mathrm{~kg}$ ). In all IRCs, each participating household was given at least two LPG cylinders for the duration of the trial, and was instructed to request a refill when the first cylinder was empty. In the research settings in Guatemala, Peru, and Rwanda, research staff were responsible for the initial stove installation and for the delivery and exchange of LPG cylinders. In India, stove installation and LPG cylinder delivery/exchange were conducted directly by a contracted local LPG distribution company, as required by Indian regulations.

Behavioral support of exclusive LPG use (and concurrent discouragement of traditional stove use) was another component of the intervention. Formative research influenced the exact form of these activities in each IRC (see [14]), but across all four IRCs these activities included: (1) a pledge requested of all intervention households at the start of intervention, by which they agreed to use the LPG stove for all their household cooking needs for the duration of the trial; (2) a training session when the intervention was delivered, covering the safety and usage of the LPG equipment; and (3) tailored messages and materials provided at the start of the intervention and thereafter as needed, to encourage and support the exclusive use of LPG and to discourage any continued use of traditional stoves.

Although a large portion of the behavioral support of LPG use (as described above) occurred at the start of the study upon stove installation, additional behavioral reinforcement was provided as needed upon detection of traditional stove use in an intervention household. At these visits, the behavioral reinforcement team spoke with household members about their cooking needs, and a survey was completed to document the participants' reported reasons for using their traditional stove. The team used the survey responses 
to lead a discussion with the family about ways to shift future cooking activities to the LPG stove.

\subsection{Measuring Intervention Fidelity}

Intervention fidelity (to what extent the intervention was delivered as intended) was assessed using the following indicators:

Installation of the intervention package shortly after trial enrollment: Given that the participants were pregnant women, the timing of the intervention was critical to enable as much coverage by the intervention during gestation as possible. The key metric for this indicator was the time between the visit to randomize the household to intervention or control—conducted in a blinded fashion using a choice of sealed envelopes—and delivery/installation of the stove package (target: < 14 days post-randomization).

Consistent LPG fuel delivery, at a level sufficient to meet all cooking needs, with no gaps in fuel that prompt the use of biomass fuels: Our protocol specified that LPG refills should be delivered within one week of a participant's request, as the household was instructed to switch to their second cylinder of gas and call to request a refill as soon as their first cylinder ran out. In all IRCs, the fuel cylinder size provided was expected to cover all cooking needs for more than seven days, making it unlikely that participants would deplete their second cylinder while waiting for delivery of a replacement. Here, we calculated the average time between the request and delivery of refill LPG cylinders over gestation (target: $<7$ days), as well as the frequency of reports that indicated that a household ran out of LPG fuel and had to revert to cooking with traditional stoves during the gestational period.

Maintenance and repairs ensuring that the equipment functioned properly and that issues were addressed quickly: Proper maintenance of the LPG stove and cylinder was checked at every prenatal LPG delivery visit. Participants were encouraged to contact study staff between visits if their stove required maintenance or repair. We tabulated the number of repairs completed and the time between the request and fulfilment of repairs.

Behavioral support and reinforcement of exclusive LPG use: Fidelity of behavioral reinforcement was defined as the percentage of households receiving the initial LPG equipment training, the percentage of households who agreed to the LPG stove use pledge, and the percentage of households with documented traditional stove use who received at least one behavioral reinforcement visit during pregnancy.

These household-level metrics were then summarized within each IRC as well as across the total study sample.

\subsection{Measuring Intervention Adherence}

Intervention adherence had two key and interrelated components: use of the intervention stove and disuse of traditional stoves. These two aspects of stove use were assessed using a combination of questionnaires, stove use monitors, and visual observations by research staff.

First, we collected self-reported stove use data using questionnaires at baseline and at two follow-up visits during pregnancy (at 24-28 and 32-36 weeks' gestation). Relevant questions were asked about which stoves were used in the previous $24 \mathrm{~h}$.

Quantitative stove use monitoring was conducted using stove use monitors (SUMs) [19]. SUMs were primarily used to assess traditional stove use, and were deployed on all traditional stoves (defined as any stove using biomass fuel (e.g., wood, dung, or charcoal) or kerosene) in intervention households upon installation of the LPG stove. The choice to deploy SUMs preferentially on traditional, versus LPG, stoves was motivated by the understanding that exposure to household air pollution (HAP) from traditional stoves must be nearly eliminated in order to achieve clinically meaningful reductions in exposure [13]. SUMs were left in place continuously through to the end of follow-up, with data downloaded every two weeks. For budgetary reasons SUMs were not routinely installed on LPG stoves, although a convenience subset of $\sim 20 \%$ of the intervention households did 
have SUMs installed on their LPG stoves to inform household air pollution models [15]. Details on algorithms used to detect cooking events using SUMs can be found in the Supplementary Materials. In brief, temperature recordings exceeding thresholds specific to each setting and type of stove (LPG stove vs. traditional stove) and lasting for at least $5 \mathrm{~min}$ were used to identify cooking events. Measurements following indications of instrument malfunction (e.g., thermocouple errors) were discarded, and households with less than two continuous weeks of SUM data during pregnancy were excluded from SUM analyses.

Visual observations, made by study staff, were the last component of adherence tracking: at every visit to the household during pregnancy (e.g., to collect anthropometric measurements, biological samples, or exposure data), research staff were asked to observe the kitchen and outdoor cooking spaces and to file a report if there was evidence of current or recent traditional stove use (e.g., a biomass-burning stove currently in use or with ashes/heat, indicating recent use). These observations were intended to catch the use of temporary traditional fires and as a check on SUM data, and would trigger behavioral reinforcement visits to the household. All questionnaire and visual observation data for the trial were recorded in REDCap [20].

Stove use data were aggregated at the daily level, and categorized as days with any detected traditional stove use versus days with none. In households with SUMs, we calculated traditional stove use as a proportion of valid stove-use-monitored days: i.e., the number of days in the household with usage of a traditional stove detected, divided by the total number of days with valid SUMs measurements in that household. As a metric of adherence, we also report the number of households who had less than one day with traditional stove use per 30 days (one month) of observation. If a household destroyed or stored their traditional stove at the start of the trial and visual observations did not indicate subsequent installation/use of another, that household was assumed to have 0 days of traditional stove use over the period of observation.

\subsection{Stove Use in Control Households}

The questionnaires to assess stove use in intervention households in the last $24 \mathrm{~h}$ (at baseline, 24-28, and 32-36 weeks' gestation) were also deployed in control households. These data were analyzed to investigate if there was any uptake of LPG stoves in control households over the follow-up period.

\section{Results}

\subsection{Study Population and Procedures}

Between May 2018 and February 2020, 3195 pregnant women across the four research settings were enrolled in the trial and randomized to either intervention or control groups (Table 1). Five women randomized to the intervention group did not receive the LPG stove because they: left the catchment area $(n=1)$, miscarried between randomization and stove delivery $(n=1)$, or withdrew $(n=3)$. An additional 130 women exited prior to or at delivery of the infant for reasons such as maternal death $(n=1)$, miscarriage/abortion $(n=15)$, moving away $(n=19)$, refusal/withdrawal $(n=42)$, and stillbirth $(n=53)$. The last birth occurred in September 2020.

\subsection{Intervention Fidelity (Delivery of the Intervention as Intended) \\ 3.2.1. Delivery of Intervention Stove}

Among the 1585 pregnant women who received the intervention, the median (Q1, Q3) elapsed time between randomization and the delivery of the intervention was $8(5,15)$ days: for Guatemala it was 9 (5, 15); India, 14 (9, 20); Peru, $5(2,7)$; and Rwanda, $11(7,20)$ (Table 2). Overall, 1156 households (72.9\%) had an LPG stove installed within the desired 14-day window after randomization. The median $(\mathrm{Q} 1, \mathrm{Q} 3)$ gestational age at the time of stove installation/initial fuel delivery was $17.9(15.4,20.6)$ weeks, and the median time under intervention during pregnancy was 149 days (21 weeks, or approximately 5 months).

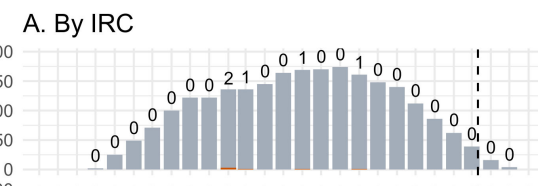

B. Total

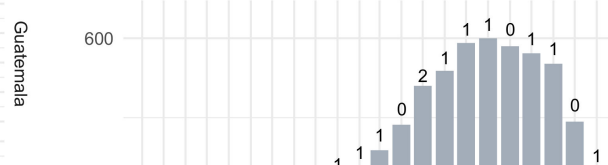


Table 2. Intervention fidelity.

\begin{tabular}{|c|c|c|c|c|c|}
\hline IRC & Guatemala & India & Peru & Rwanda & Total \\
\hline Households receiving intervention ${ }^{1}$ & 400 & 398 & 394 & 393 & 1585 \\
\hline \multicolumn{6}{|l|}{ Stove and Initial LPG Cylinder Delivery } \\
\hline $\begin{array}{l}\text { Days between randomization and } \\
\text { stove/cylinder delivery: median (Q1, Q3) }\end{array}$ & $(5.0,15.0)$ & $\begin{array}{c}14.0 \\
(9.0,20.0)\end{array}$ & $\begin{array}{l}5.0 \\
(2.07 .0)\end{array}$ & $\begin{array}{l}11.0 \\
(7.0,20.0)\end{array}$ & $\begin{array}{c}8.0 \\
(5.0,15.0)\end{array}$ \\
\hline $\begin{array}{l}\text { Intervention delivery within } 14 \text { days of } \\
\text { randomization: N (\%) }\end{array}$ & $286(71.5 \%)$ & $218(54.8 \%)$ & $393(99.7 \%)$ & $259(65.9 \%)$ & $1156(72.9 \%)$ \\
\hline $\begin{array}{l}\text { Gestational age at start of intervention } \\
\text { (weeks): median }(\mathrm{Q} 1, \mathrm{Q} 3)\end{array}$ & $17.5(15.4,20.6)$ & $18.7(16.4,21.7)$ & $17.4(14.6,20.1)$ & $18.0(15.7,20.4)$ & $17.9(15.4,20.6)$ \\
\hline $\begin{array}{l}\text { Days under intervention during pregnancy } \\
\text { (installation date to the end of gestation): } \\
\text { median }(\mathrm{Q} 1, \mathrm{Q} 3)\end{array}$ & $\begin{array}{c}150.0 \\
(131.0,167.0)\end{array}$ & $\begin{array}{c}139.0 \\
(120.0,157.0)\end{array}$ & $\begin{array}{c}153.5 \\
(134.0,176.0)\end{array}$ & $\begin{array}{c}153.0 \\
(135.0,170.0)\end{array}$ & $\begin{array}{c}149.0 \\
(130.0,168.0)\end{array}$ \\
\hline \multicolumn{6}{|l|}{ LPG Refill Delivery } \\
\hline $\begin{array}{l}\text { Time between request and delivery (days) }{ }^{2} \text { : } \\
\text { median (Q1, Q3) }\end{array}$ & $\begin{array}{l}2.2 \\
(1.9,2.6)\end{array}$ & $\begin{array}{l}5.0 \\
(3.0,7.5)\end{array}$ & $\begin{array}{c}0.0 \\
(0.0,0.0)\end{array}$ & $\begin{array}{c}1.3 \\
(0.5,3.3)\end{array}$ & $\begin{array}{c}1.9 \\
(0.0,3.3)\end{array}$ \\
\hline \multicolumn{6}{|l|}{ Stove Use Reinforcement } \\
\hline $\begin{array}{l}\text { Participants who agreed to the stove use } \\
\text { pledge: } N(\%)\end{array}$ & $400(100 \%)$ & $398(100 \%)$ & $394(100 \%)$ & $393(100 \%)$ & $1585(100 \%)$ \\
\hline $\begin{array}{l}\text { Participants who received LPG stove } \\
\text { training: } N(\%)\end{array}$ & $399(99.8 \%)$ & $388(97.5 \%)$ & $392(99.5 \%)$ & $392(99.8 \%)$ & $1571(99.1 \%)$ \\
\hline $\begin{array}{l}\text { Participants with traditional stove use (TSU) } \\
\text { who received a behavioral reinforcement } \\
\text { visit: N (\% of those with TSU) }\end{array}$ & $52(57.1 \%)$ & $3(7.7 \%)$ & $175(79.9 \%)$ & $121(71.6 \%)$ & $351(67.8 \%)$ \\
\hline
\end{tabular}

${ }^{1}$ A total of $n=5$ households randomized to intervention ( 2 in India, 2 in Peru, and 1 in Rwanda) exited the study after randomization and before LPG stove delivery. ${ }^{2}$ Data on delays in timely LPG delivery assume that participants requested LPG by phone prior to fieldworker visits. In some cases, participants did not call for LPG deliveries in advance of bi-weekly fieldworker visits, yielding an interval of 0 days between request and refill (most common in Peru). Given the low reporting rate of running out of LPG (Figure 2), any lack of prior refill requests does not appear to have substantially affected the continuity of LPG supply.

\subsubsection{LPG Cylinder Refills}

Across the trial, there were 10,856 total LPG cylinder refills during gestation. The median $(\mathrm{Q} 1, \mathrm{Q} 3)$ time between the request and delivery of LPG cylinders was $1.9(0.0,3.3)$ days across all IRCs, well within the 7-day window specified in the protocol. The number of intervention participants who ever reported that they used their traditional stove because they ran out of LPG during pregnancy was $62(3.9 \%): 5(1.3 \%)$ in Guatemala, $0(0 \%)$ in India, 26 (6.6\%) in Peru, and 31 (7.9\%) in Rwanda. We also provide a figure showing the number of households that reported this issue by month of follow-up (Figure 2). There were no obvious monthly trends in these reports, even considering the start of the COVID-19 pandemic in March 2020: fewer than 5\% of total enrolled households reported running out of LPG in any month of follow-up. Notably, $85 \%$ of the pregnant women in the intervention households gave birth (or exited the study before birth) prior to the start of the COVID-19 pandemic: $n=367$ (92\%) in Guatemala, $343(86 \%)$ in India, 274 (70\%) in Peru, and $362(92 \%)$ in Rwanda.

\subsubsection{Repairs}

Repairs were conducted on the LPG stove system in 187 households (11.8\%) during pregnancy. The wait time in days between the reporting of a stove problem and a successful repair was on average less than one day (Table S2). In most cases, the stove was still usable despite the problem. Often it was the fieldworker who discovered a slight problem upon a household visit to check on the stove. 


\subsubsection{Stove Use Reinforcement}

Of the intervention participants, $100 \%$ agreed to the stove use pledge, and pregnant women participated in initial stove use training in $99.1 \%$ of the households (Table 2). In the few cases where the pregnant woman was not present, other household members participated in the training; field staff followed-up at subsequent visits to ensure that the pregnant woman was comfortable using the LPG stove.

A total of 351 intervention households were visited for follow-up behavioral reinforcement: $n=52$ in Guatemala, 3 in India, 175 in Peru, and 121 in Rwanda (Table 2). This represents $68 \%$ of the 517 participants ( $33 \%$ of the intervention arm) who ever had traditional stove use flagged by SUMs or direct observation during pregnancy (Table 3 and Figure 3).

\subsection{Intervention Adherence (Stove Use)}

We provide a summary of traditional stove use in the intervention households across the trial in Figure 3, and by IRC in Table 3. As noted above, the primary use of SUMs was to monitor traditional stove use following LPG stove installation in the intervention households. Although the intervention households were not asked to remove or alter their traditional stoves in any way, a substantial proportion of them, particularly in Guatemala ( $n$ $=266,66.5 \%)$ and India $(n=212,53.2 \%)$, destroyed or stored their traditional stove(s) upon installation of the LPG stove. A smaller number of households in Peru $(n=8,2.0 \%)$ and Rwanda ( $n=12,3.1 \%$ ) also destroyed or stored their traditional stoves. Of the remaining 1087 households that retained their traditional stoves, SUM data met validity criteria for 1042 (99.1\%); coverage of stove-use-monitoring over pregnancy was high (median (Q1, Q3) coverage: $100 \%(73.3 \%, 100 \%)$ of gestational follow-up time). In over half $(59.5 \%)$ of these households, no traditional stove use was detected during the monitoring period. Of all the households, $86.2 \%$ either destroyed their traditional stove, retained the stove but did not use it, or used it infrequently ( $<1$ day per month, Figure 4$)$. 
Table 3. Traditional stove use (TSU) in the intervention households during pregnancy.

\begin{tabular}{|c|c|c|c|c|c|}
\hline IRC & Guatemala & India & Peru & Rwanda & Total \\
\hline Households receiving intervention & 400 & 398 & 394 & 393 & 1585 \\
\hline \multicolumn{6}{|c|}{ Households who Destroyed Traditional Stoves (no SUMs) } \\
\hline $\begin{array}{l}\text { Households who destroyed/stored traditional } \\
\text { stove upon intervention: N (\%) }\end{array}$ & $266(66.5 \%)$ & $212(53.3 \%)$ & $8(2.0 \%)$ & $12(3.1 \%)$ & $498(31.4 \%)$ \\
\hline $\begin{array}{l}\text { Households with subsequent positive visual } \\
\text { ID of TSU: N (\% of those who destroyed) }\end{array}$ & $43(16.2 \%)$ & $0(0.0 \%)$ & $1(12.5 \%)$ & $0(0.0 \%)$ & $44(8.8 \%)$ \\
\hline \multicolumn{6}{|c|}{ Households who Retained Traditional Stoves (SUMs Installed) } \\
\hline $\begin{array}{l}\text { Households retaining a traditional stove: } \\
\mathrm{N}(\%)\end{array}$ & $134(33.5 \%)$ & $186(46.7 \%)$ & $386(98.0 \%)$ & $381(96.9 \%)$ & $1087(68.6 \%)$ \\
\hline $\begin{array}{l}\text { Households with valid SUM data ( } \geq 2 \text { weeks } \\
\text { during gestation): } \mathrm{N} \text { ( } \% \text { of those retaining a } \\
\text { traditional stove) }\end{array}$ & $132(99.2 \%)$ & $185(100.0 \%)$ & $386(100.0 \%)$ & $339(97.7 \%)$ & $1042(99.1 \%)$ \\
\hline $\begin{array}{l}\text { Days of stove-use-monitoring per household: } \\
\text { median (Q1, Q3) }\end{array}$ & $99.0(29.8,146.0)$ & $127.0(92.0,148.0)$ & $\begin{array}{c}144.5 \\
(121.2,170.0)\end{array}$ & $133.0(92.5,160.0)$ & $\begin{array}{c}134.0 \\
(97.0,160.0)\end{array}$ \\
\hline $\begin{array}{l}\text { Proportion of gestational follow-up time } \\
\text { monitored by SUMs: Median (Q1,Q3) }\end{array}$ & $69.3(21.6,100.0)$ & $100.0(81.5,100.0)$ & $100.0(97.9,100.0)$ & $100.0(67.6,100.0)$ & $\begin{array}{c}100.0 \\
(73.3,100.0)\end{array}$ \\
\hline $\begin{array}{l}\text { Percent of stove-use-monitored days with TSU } \\
\text { detected: Median (Q1, Q3) }\end{array}$ & $0.0(0.0,0.0)$ & $0.0(0.0,0.0)$ & $0.6(0.0,3.6)$ & $0.0(0.0,1.4)$ & $0.0(0.0,1.6)$ \\
\hline $\begin{array}{l}\text { Households with no SUM-detected TSU } \\
\text { during pregnancy: } \mathrm{N}(\%)^{1}\end{array}$ & $105(79.5 \%)$ & $146(78.9 \%)$ & $176(45.6 \%)$ & $193(56.9 \%)$ & $620(59.5 \%)$ \\
\hline $\begin{array}{l}\text { Households with }<1 \text { day with TSU per } 30 \\
\text { days of monitoring: } \mathrm{N}(\%)^{1}\end{array}$ & $118(89.4 \%)$ & $170(91.9 \%)$ & $287(74.4 \%)$ & $293(86.4 \%)$ & $868(83.3 \%)$ \\
\hline $\begin{array}{l}\text { Traditional stove cooking minutes per day, } \\
\text { among those with } \geq 1 \text { day of TSU in gestation: } \\
\text { median (Q1, Q3) (N hh) }\end{array}$ & $\begin{array}{c}138.0(41.2,385.3) \\
\quad(n=27)\end{array}$ & $\begin{array}{l}85.0(48.9,121.5) \\
\quad(n=39)\end{array}$ & $\begin{array}{l}95.0(54.4,131.7) \\
\quad(n=210)\end{array}$ & $\begin{array}{l}81.7(43.8,151.7) \\
\quad(n=146)\end{array}$ & $\begin{array}{c}91.0 \\
(47.5,142.4) \\
(n=422)\end{array}$ \\
\hline \multicolumn{6}{|c|}{ Overall TSU } \\
\hline $\begin{array}{l}\text { No TSU detected by SUMs or visual } \\
\text { observation: } \mathrm{N}(\%)\end{array}$ & $309(77.2 \%)$ & $359(90.2 \%)$ & $175(44.4 \%)$ & $224(57.0 \%)$ & $1068(67.4 \%)$ \\
\hline $\begin{array}{l}\text { Any TSU detected by SUMs or visual } \\
\text { observation: } \mathrm{N}(\%)\end{array}$ & $91(22.8 \%)$ & $39(9.8 \%)$ & $219(55.6 \%)$ & $168(42.7 \%)$ & $517(32.6 \%)$ \\
\hline
\end{tabular}

${ }^{1}$ Percent of households with valid SUM data.

Visual observations at household visits were used as a check on SUM data and to identify newly built or installed traditional stoves (to detect the use of stoves as yet unequipped with SUMs). Our data suggest that the existence of unobserved traditional stoves was rare: over the course of participant follow-up during pregnancy, fieldworkers recorded over 16,000 visual observations in households, and among these only $122(0.8 \%)$ indicated a recently used traditional stove with no SUMs installed. Altogether, the complete abandonment of traditional stoves (no traditional stove use detected via SUMs or visual observations) was observed among $67.4 \%$ of the households (Table 3 and Figure 3).

A small fraction of the intervention households reported needs that resulted in the use of traditional stoves (Table 4). Among them, reasons included the need to cook large quantities of food, to prepare particular dishes, other household members using the traditional stove, issues with LPG supply, or concerns about its safety. The histograms in Figure 5A present data using SUMs, demonstrating that very few of the intervention households in any IRC used their traditional stoves on more than $10 \%$ of monitored days. In the households where SUMs detected traditional stove use, the cooking time per day on traditional stoves was, on average, $91 \mathrm{~min}$ (approximately $1.5 \mathrm{~h}$, Table 3 ). 


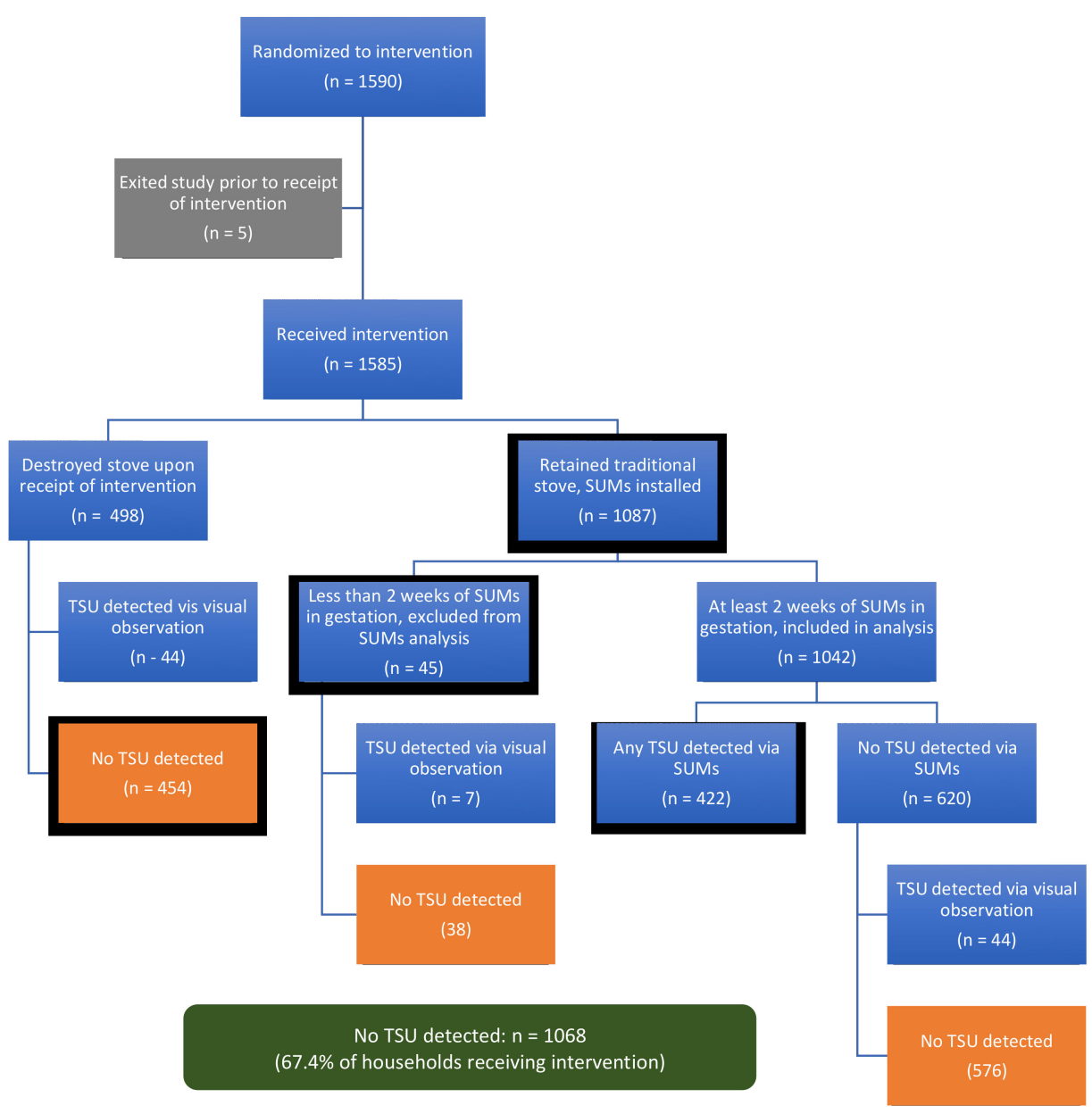

Figure 3. Traditional stove use (TSU) in the intervention households during pregnancy.

Table 4. Top reasons reported for traditional stove use among the intervention households during pregnancy.

\begin{tabular}{|c|c|}
\hline IRC & $\begin{array}{c}\text { Top Three Ranked Reasons for Traditional Stove Use (N Reporting; } \\
\text { Percent of the Intervention Households) }\end{array}$ \\
\hline Guatemala & $\begin{array}{l}\text { 1. Needing to cook large quantities of food for special occasions }(32 ; 8.0 \%) \\
\text { 2. Challenges with cleaning or maintaining the LPG stove }(20 ; 5.0 \%) \\
\text { 3. Preparing a traditional dish }(14 ; 3.5 \%)\end{array}$ \\
\hline India & $\begin{array}{l}\text { 1. Unsure how to check for or respond to a leak }(1 ; 0.3 \%) \\
\text { 2. Challenges with cleaning or maintaining the LPG stove }(1 ; 0.3 \%) \\
\text { 3. General feeling of insecurity with the LPG stove }(1,0.3 \%) \\
\text { 4. }\end{array}$ \\
\hline Peru & $\begin{array}{l}\text { 1. Other household members using the traditional stove }(72 ; 18.3 \%) \\
\text { 2. Preparing a traditional dish (i.e., burning lamb's head in the traditional } \\
\text { stove) }(33 ; 8.4 \%) \\
\text { 3. Running out of LPG }(28 ; 7.1 \%)\end{array}$ \\
\hline Rwanda & $\begin{array}{l}\text { 1. Running out of LPG }(32 ; 8.1 \%) \\
\text { 2. Other household members using the traditional stove }(11 ; 2.8 \%) \\
\text { 3. Concerns about the LPG cylinder exploding/burns }(7 ; 1.8 \%)\end{array}$ \\
\hline
\end{tabular}




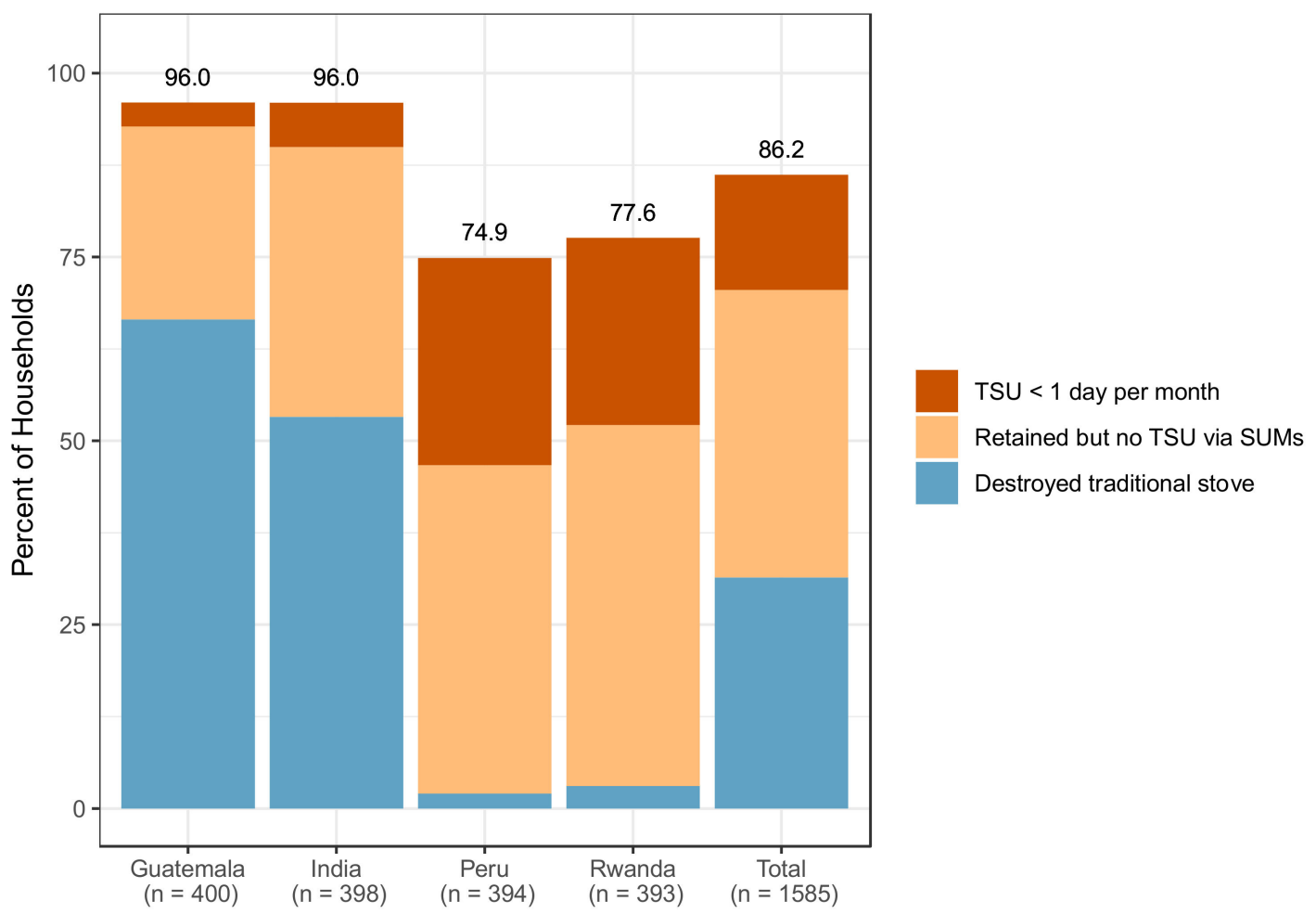

Figure 4. Disuse of traditional stoves in the intervention households. Each stacked bar represents the percent of the intervention households in an IRC who either: destroyed their traditional stove upon LPG installation (blue); retained their traditional stove but no evidence of use was observed over the gestational period (using SUMs, sepia); or used their traditional stove on less than one occasion per month over the gestational period (using SUMs, red). Numbers on top of each bar represent the sum of these categories in each IRC. The total bar presents the average across all four IRCs.

SUM data for LPG stoves during the gestational period were available in a convenience sample of 244 (15.4\%) of the intervention households: 55 (13.8\%) in Guatemala, $110(27.6 \%)$ in India, 50 (12.7\%) in Peru, and 29 (7.4\%) in Rwanda (Table 5 and Figure 5B). In these homes, LPG stove use was detected on $98.3 \%$ of the monitored days, with a median of $99 \%$ of days in Guatemala, 93.8\% in India, 99.3\% in Peru, and 98.3\% in Rwanda. The median time spent using the LPG stove by household was $232 \mathrm{~min}$ (over $3.8 \mathrm{~h}$ ) a day (Guatemala, 299 min; India, 197; Peru, 285; and Rwanda, 231).

Finally, stove use data collected by a questionnaire for the intervention households (Figure 6A) demonstrate a shift in self-reported stove use behavior between the baseline and post-intervention visits. Between $93 \%$ and $100 \%$ of the intervention households reported traditional stove use in the previous $24 \mathrm{~h}$ at baseline. At the first follow-up visit (24-28 weeks gestation), less than $4 \%$ of the intervention households in any IRC reported using traditional stoves over the previous $24 \mathrm{~h}$. These levels remained largely unchanged at the second visit (32-36 weeks gestation). Meanwhile, between $96 \%$ and $98 \%$ of the intervention households at each of the four sites reported exclusive use of the LPG stove in the previous $24 \mathrm{~h}$ at both post-intervention visits. 


\section{A. Traditional stove use}

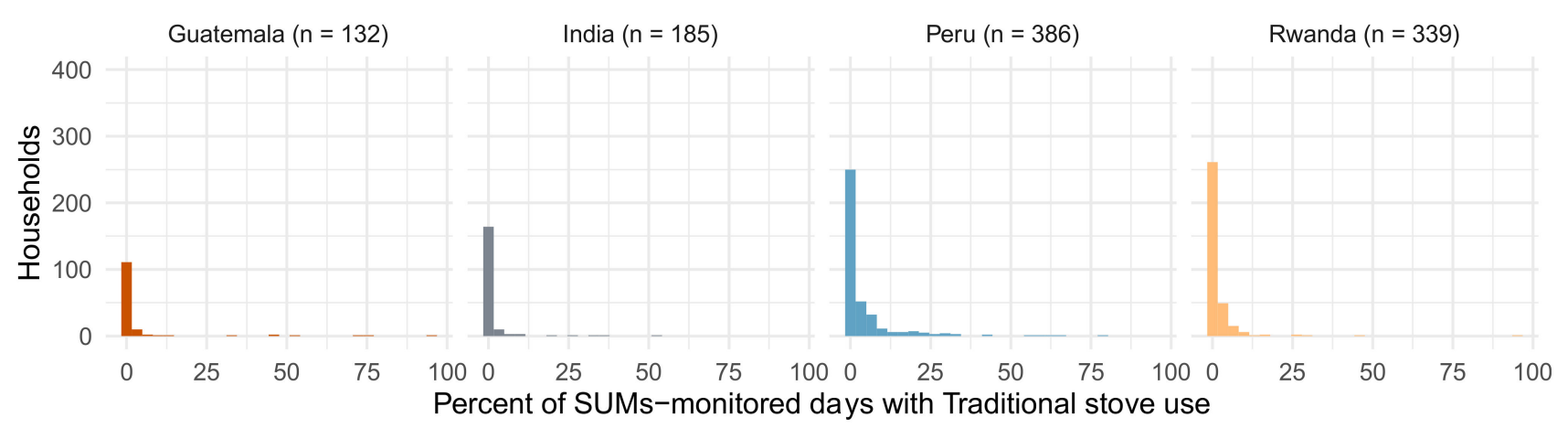

B. LPG stove use

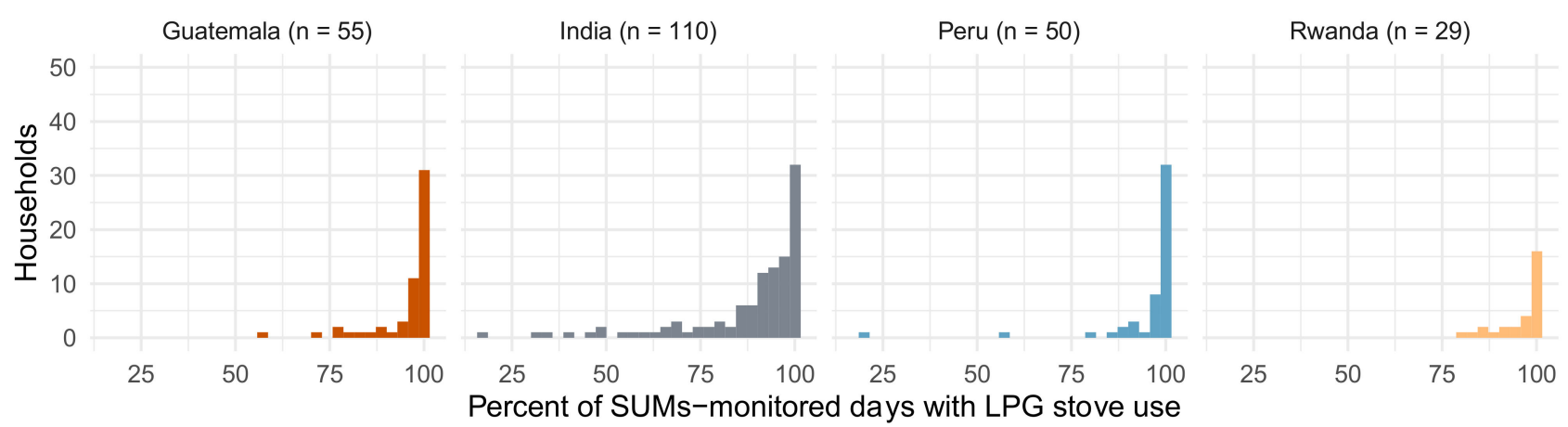

Figure 5. Intervention households' stove use in gestation as measured by SUMs. (A) Percent of stove-use-monitored days with traditional stove use detected via SUMs in the intervention households during pregnancy. Note that protocol called for all the intervention households ( 400 in each IRC) to be followed with SUMs installed on traditional stoves, but many households (particularly in Guatemala and India) destroyed their traditional stoves and thus SUMs could not be installed. (B) Percent of stove-use-monitored days with LPG stove use detected via SUMs in the intervention households during pregnancy. By design, SUMs were only installed on LPG stoves in a subset of homes.

Table 5. LPG stove use in the intervention households during pregnancy via SUMs.

\begin{tabular}{|c|c|c|c|c|c|}
\hline IRC & Guatemala & India & Peru & Rwanda & Total \\
\hline Households receiving intervention & 400 & 398 & 394 & 393 & 1585 \\
\hline $\begin{array}{l}\text { Households with SUMs on LPG stove } \geq 2 \text { wks } \\
\text { during gestation: } N(\%)\end{array}$ & $55(13.8 \%)$ & $110(27.6 \%)$ & $50(12.7 \%)$ & $29(7.4 \%)$ & $244(15.4 \%)$ \\
\hline Days of monitoring: median $(\mathrm{Q} 1, \mathrm{Q} 3)$ & $\begin{array}{c}128.0 \\
(119.0,142.0)\end{array}$ & $\begin{array}{c}127.0 \\
(101.2,148.8)\end{array}$ & $\begin{array}{c}116.0 \\
(48.2,134.0)\end{array}$ & $\begin{array}{c}112.0 \\
(76.0,130.0)\end{array}$ & $\begin{array}{c}123.0 \\
(97.8,142.0)\end{array}$ \\
\hline $\begin{array}{l}\text { Percent of stove-use-monitored days with LPG } \\
\text { stove use detected: median (Q1, Q3) }\end{array}$ & $99.0(96.1,100.0)$ & $93.8(84.9,99.4)$ & $99.3(97.2,100.0)$ & $99.3(94.7,100.0)$ & $\begin{array}{c}98.3 \\
(90.5,100.0)\end{array}$ \\
\hline $\begin{array}{l}\text { LPG stove cooking minutes per day of LPG stove } \\
\text { use, among those with } \geq 1 \text { day of LPG stove use } \\
\text { in gestation: median }(\mathrm{Q} 1, \mathrm{Q} 3)(\mathrm{N} \mathrm{hh})\end{array}$ & $\begin{array}{c}299.3 \\
(223.4,439.8) \\
(n=55)\end{array}$ & $\begin{array}{l}197.0 \\
(159.7,248.8) \\
(n=110)\end{array}$ & $\begin{array}{c}285.4 \\
(226.4,341.0) \\
(n=50)\end{array}$ & $\begin{array}{c}231.2 \\
(187.7,292.3) \\
(n=29)\end{array}$ & $\begin{array}{c}232.5 \\
(181.3,301.6) \\
(n=244)\end{array}$ \\
\hline
\end{tabular}

\subsection{Stove Use in Control Arm}

The primary means of assessing stove use in the control arm was by self-reporting. As in the intervention arm, between $94 \%$ and $100 \%$ of participants randomized to the control arm in each IRC reported use of a traditional stove in the last $24 \mathrm{~h}$ at baseline (Figure 6B). In Guatemala, India, and Rwanda, there was virtually no reported LPG use in control households during pregnancy (under $2 \%$ reporting exclusive LPG use, and very little stacking with traditional stoves and LPG, whether at baseline or follow-up).

Self-reported LPG use among controls was higher in Peru compared to the other IRCs: $6 \%$ of control households reported exclusively using an LPG stove in the past $24 \mathrm{~h}$ at the baseline visit, $22 \%$ at the first pregnancy follow-up visit, and $23 \%$ at the second follow-up 
visit. Although substantial, these numbers are still much smaller than the proportion of the intervention households in Peru that reported exclusive LPG use at follow-up (96-97\%) (Figure 6A).

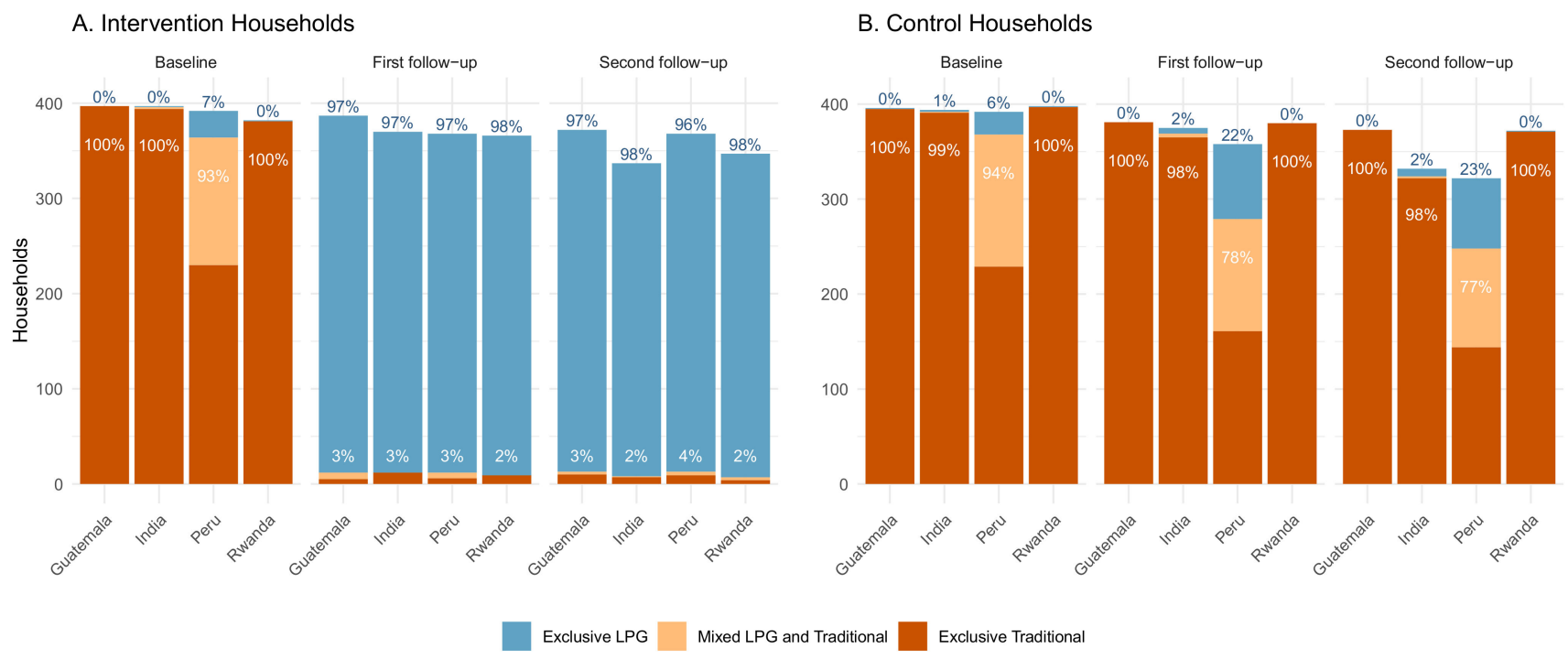

Figure 6. Self-reported stove use. Self-reported stove use in the last $24 \mathrm{~h}$ by intervention (A) and control (B) households at baseline, 1st prenatal exposure monitoring visit (24-28 weeks gestation), and 2nd prenatal exposure monitoring visit (32-36 weeks gestation). Percentages in white are the percent of households, out of the total reporting, that reported any traditional stove use in the previous $24 \mathrm{~h}$ (exclusively traditional and/or mixed LPG and traditional). Percentages in blue are the percent of households that reported exclusively LPG use in the previous $24 \mathrm{~h}$.

\section{Discussion}

Answering our trial's fundamental study question-the effect of a clean fuel intervention on human health-requires successful intervention fidelity and adherence. These are prerequisites in the theory of change (Figure 1) to the potential for achieving the exposure reductions believed to be necessary for health gains. In the HAPIN study, an intervention for pregnant women consisting of a multi-burner LPG stove, two cylinders of LPG fuel, and continuous free home delivery of LPG—combined with adequate training and support-can result in a near-complete transition of cooking practices from traditional stoves to LPG during the latter half of gestation: a finding that, to our knowledge, has not been previously reported. Specifically, LPG shortages were reported by less than $4 \%$ of the intervention households over the duration of pregnancy. Over $96 \%$ of the intervention households reported exclusive use of LPG for cooking at each pregnancy follow-up visit. Delivery of LPG across trial participants was robust, and LPG stoves were well-constructed, with repairs seldom needed. We report a complete transition to exclusive cooking with LPG during pregnancy among over two-thirds of our intervention participants, and minimal stacking with traditional stoves among the others. In over $86 \%$ of the intervention households, traditional stoves were either not used at all or used less than 1 day per month of follow-up. These findings were upheld across four distinct study settings, speaking to the generalizability of this specific intervention to different locations with varying cooking practices and cultural contexts.

We report several successes related to intervention fidelity and adherence: first, we succeeded in securing consistent access to the intervention among the study participants, by making the fuel free and delivering it directly to participants' homes. This access continued despite disruptions associated with the COVID-19 global pandemic. Upon receiving permission from local authorities and following strict COVID-19 prevention and disease control protocols [21], we were able to continue to provide fuel with little 
interruption, largely because the delivery of household cooking fuel was considered an essential activity in each of our four study regions. We also succeeded in enabling nearexclusive use of the LPG stoves and simultaneous disuse of traditional stoves among the intervention arm participants.

These results are in sharp contrast to previous trials of improved biomass cookstoves, where continued use of traditional stoves was common. In Michoacán, Mexico, for example, adherence to an improved biomass stove intervention was only 50\% [22]. In Malawi, use of an improved biomass intervention stove declined over time, with a quarter of the trial households abandoning the intervention stove after one year [2]. By contrast, less stacking with traditional stoves has been reported in previous trials that, similar to ours, intervened with LPG stoves, and where both stoves and fuel were available at no cost to the participants $[6,8]$.

The effectiveness of an environmental intervention to reduce HAP at the household level in low- and middle-income country settings requires that three conditions are met: the intervention must be able to meaningfully reduce important exposures (efficacy); it must reach populations with high levels of exposure to HAP (fidelity); and it must be taken up and used consistently, if not exclusively (adherence). Until recently, efforts to reduce HAP largely failed to meet the first condition, as improved biomass cookstoves were unable to achieve necessary targets in indoor air quality [2,23-25]. However, a shift of focus within the sector from improved biomass cookstoves to cleaner fuels such as LPG and electricity, which have been shown to more consistently reduce HAP exposure to levels below WHO guidelines [26], has been a solution to the efficacy issue. Furthermore, the acceptance of LPG as an exclusive cooking technology in different settings suggests that cooks in a diversity of settings accept and even embrace this technology, finding it well-suited to meet a variety of cooking tasks. LPG is regarded by many as a fast, convenient, and cleaner way to cook (e.g., [27-31]). When efforts have been made at an appropriate scale to transition large populations to LPG for cooking, they have often been successful (e.g., [32-34]), as long as financial barriers to adoption were removed. Notably, however, stacking with traditional fuels remains extremely common in the context of large-scale governmental efforts to promote LPG for cooking [35].

The primary challenges for clean fuel uptake are related to fidelity and adherence, as the adoption and sustained use of clean fuels at scale faces a number of daunting obstacles. A robust supply chain of LPG fuel must be reliably available at a cost that is affordable to end users [36], and demand must exist to support the supply. LPG cylinders are heavy, even when empty, and newly filled cylinders must regularly reach the household to replace depleted ones. Using an LPG stove requires learning new behaviors, such as lighting the stove, regulating the flame, and checking for safety. Stoves must withstand repeat use, and repairs or replacement must be readily and easily available. Finally, the achievement of health goals will necessitate not only adoption of the new technology, but the simultaneous disadoption of older, customary cooking habits, as even an occasional reversion to traditional stoves can result in excessive exposure to HAP [13]. For the purposes of HAPIN, we planned and piloted both intervention and behavior change communication strategies, including the provision of the stove and fuel intervention free of charge. We worked with local stove manufacturers and LPG companies who provided invaluable experience, advice, and training to trial staff. We assumed responsibility for ensuring consistent stove and cylinder deliveries and repairs, including the provision of two cylinders to each home for easy switching when one cylinder was depleted. We monitored stove use continuously and provided behavioral messaging when traditional stove use was detected by either observation or self-reporting during home visits or by SUMs [14]. We believe the high level of exclusive LPG use observed during pregnancy in this trial to be due to the combination of several factors, namely the acceptability/likeability of the LPG stove and fuel system by the participants; the fact that its provision was free; and the investments of time and labor by our trial staff in training, supporting, and reinforcing exclusive LPG use throughout the trial. 
As a result, the study is well-positioned to achieve the reductions in exposure that are thought to be necessary to effect measurable change in birth weight [37].

However, the transferability of this success should not be assumed under conditions where stoves and fuel are accessed through conventional supply chains and where consistent use requires that they be affordable, available, and prioritized by low-income households. Achieving the levels of adoption and use that we observed will almost certainly require government initiatives to further promote access, especially to households well-beyond the proverbial "last mile" [38,39]. Clean fuel programs will also likely require subsidies to reduce the cost of fuel for populations at the base of the economic pyramid [33]. If the intervention achieves significant health gains, some have argued these costs could potentially be offset by savings to the health system [40]. Limiting an intervention to gestation and the first year of a child's life will reduce its implementation cost, but it is unclear how that may impact future patterns of clean cooking. Still, our study provides compelling evidence that a targeted intervention can be successful in reaching a vulnerable population and that they will willingly accept it, in a manner that has the potential to achieve durable gains in health and development.

There were some potential shortcomings in our study. While we employed multiple complementary strategies to detect traditional stove use in the intervention households, occasional traditional stove use events may have eluded detection. For example, participants and/or their families may have constructed temporary-and undetected-open fires outside the household to cook for large events or to burn trash, and SUM algorithms may have occasionally missed traditional stove use events despite their careful calibration. We feel confident, nonetheless, that the multiple checks put in place to detect traditional stove use (SUMs downloading/placement checking every two weeks; visual observations whenever possible) were successful in capturing the vast majority of traditional stove use events, and that any occasional missed events would not impact our overall findings on adherence.

Another limitation is that, given our emphasis on the detection of traditional stove use events, the bulk of the trial's stove use monitors were deployed on traditional stoves in the intervention households. We therefore are unable to provide a complete picture of stove use-across LPG and traditional stoves-for more than a small subset of enrolled homes. While this strategy was well-suited to meeting the needs of the trial, it does limit complex analyses of stove use behavior (e.g., of daily or meal-by-meal patterns of cooking across multiple types of stoves) to the subset of homes where LPG stoves, as well as traditional ones, were monitored with SUMs. Despite this limitation, we feel that the results provided here present the most comprehensive data to date on the successful adoption and sustained exclusive use of an interventional cookstove during the prenatal period, as relevant to exposure in utero and infant birth weight. After the conclusion of the trial, a future publication will focus on fidelity and adherence to the intervention during the year of follow-up post infant birth, as these are relevant to postnatal exposures and downstream health outcomes. These data will be interesting to compare to the ones reported here as the intervention will have been in homes for longer periods of time, potentially affecting adherence, repair requirements, and other issues related to sustained use.

\section{Conclusions}

In the context of a randomized controlled trial of an LPG stove and fuel intervention with behavioral reinforcement in four LMIC settings, we report high adoption of the intervention, with the majority of households randomized to the intervention completely eliminating the use of traditional stoves during pregnancy.

Supplementary Materials: The following are available online at https://www.mdpi.com/article/10 .3390/ijerph182312592/s1, Table S1: Distributional statistics of derived ambient temperatures at each IRC, and the resultant primary thresholds selected for the standard and sensitive (LPG), Table S2: Stove Repairs during Pregnancy, Table S3. SUMs in Control Households During Pregnancy, Table S4. LPG Deliveries during gestation. 
Author Contributions: Conceptualization, A.K.Q., K.N.W., S.A.H., J.P.R., J.J.M. and T.F.C.; Data Curation, A.K.Q., K.N.W., R.P. and J.W.; Formal Analysis, A.K.Q., K.N.W. and R.P.; Funding Acquisition, J.P.R., W.C., J.L.P. and T.F.C.; Investigation, K.N.W., L.M.T., J.P.M., M.A.K., A.D.A., G.T., G.R. and W.C.; Methodology, A.K.Q., K.N.W., L.M.T., S.A.H., R.P., C.Q. and A.P.; Project Administration, L.M.T., J.P.M., J.P.R., G.R., W.C., J.L.P. and T.F.C.; Supervision, T.F.C.; Writing-Original Draft, A.K.Q., K.N.W. and T.F.C.; Writing-Review and Editing, A.K.Q., K.N.W., L.M.T., S.A.H., R.P., C.Q., A.P., J.P.M., J.P.R., M.A.K., A.D.A., G.T., G.R., J.J.M., W.C., J.L.P. and T.F.C. All authors have read and agreed to the published version of the manuscript.

Funding: The HAPIN trial is funded by the US National Institutes of Health (cooperative agreement 1UM1HL134590; MPIs: Checkley, Clasen, and Peel) in collaboration with the Bill \& Melinda Gates Foundation (OPP1131279). Kendra N. Williams was additionally supported by the NIH Fogarty International Center, NINDS, NIMH, NHBLI, and NIEHS under NIH Research Training Grant D43TW009340, and by the NIH/NHLBI under Award Number T32HL007534. The findings and conclusions in this report are those of the authors, and do not necessarily represent the official position of the US National Institutes of Health or the Department of Health and Human Services. This work was supported, in whole or in part, by the Bill \& Melinda Gates Foundation (OPP1131279). Under the grant conditions of the Foundation, a Creative Commons Attribution 4.0 generic license has already been assigned to the author accepted manuscript version that might arise from this submission.

Institutional Review Board Statement: The study was conducted according to the guidelines of the Declaration of Helsinki, and approved by institutional review boards (IRBs) or ethics committees at Emory University (00089799), Johns Hopkins University (00007403), Sri Ramachandra Institute of Higher Education and Research (IEC-N1/16/JUL/54/49) and the Indian Council of Medical Research-Health Ministry Screening Committee (5/8/4-30/(Env)/Indo-US/2016-NCD-I), Universidad del Valle de Guatemala (146-08-2016) and the Guatemalan Ministry of Health National Ethics Committee (11-2016), Asociación Beneficia PRISMA (CE2981.17), the London School of Hygiene and Tropical Medicine (11664-5), the Rwandan National Ethics Committee (No.357/RNEC/2018), and Washington University in St. Louis (201611159). The study has been registered with ClinicalTrials.gov (Identifier NCT02944682).

Informed Consent Statement: Informed consent was obtained from all subjects involved in the study.

Data Availability Statement: The data that support the findings of this article are publicly available at the following DOI: https:/ / doi.org/10.15139/S3/9DDEAW.

Acknowledgments: The authors wish to thank trial participants and research staff for their invaluable contributions to this work. We particularly recognize the efforts of the following staff, who were responsible for stove delivery, gas delivery, stove use monitoring, and behavioral reinforcement. Guatemala: Roberto Otsoy, Alexander Ramirez, Francisco Ramirez, Misael Ramirez, Wagner Sanchez, Rosa Torres, and Carla Trinidad. India: Durairaj Natesan, Rengaraj Ramasamy, Meenakshi Sundarem Gopal Krishna, Priyakumar Natarajan, Sylesh Loganathan, Vinayagamurthy Agoram, Sivavadivel Subramaniyan, Velumani Manoharan, Ajith Velayudham, Shankar Murugesan, Suresh Krishna, Maruthamuthu Arunachalam, Thangadurai Ramasamy, Sakthivel Rajendhiran, Jayaseelan Kathirvel, and Aravind Sekar. Rwanda: Zoe Sakas, Bernard Muyaliyani, Florien Ndagiimana, Eric Tuyishimire, Martin Sherman, Prosper Twagirayezu, Tony Rugiara, Cedrick Mugisha, Raymond Nzabandora, Eddy Frank Muhirwe, and Michel Kamali. Peru: Edison Cueva Chambi, Wilson Mendoza Inguilla, Leonora Condori Mamani, Haydeé Catacora Pari, Uriel Flores Palomino, Blenda Abarca Diaz, Jesus Reyes, David Vilca Ticona, and Suhey Vilca Mamani. A multidisciplinary, independent Data and Safety Monitoring Board (DSMB), appointed by the National Heart, Lung, and Blood Institute (NHLBI), monitors the quality of the data and protects the safety of patients enrolled in the HAPIN trial. NHLBI DSMB: Nancy R Cook, Stephen Hecht, Catherine Karr, Joseph Millum, Nalini Sathiakumar (Chair), Paul K Whelton, and Gail G Weinmann (Executive Secretary). Program Coordination: Gail Rodgers, Bill \& Melinda Gates Foundation; Claudia L Thompson, National Institute of Environmental Health Science; Mark J. Parascandola, National Cancer Institute; Danuta M Krotoski and Marion Koso-Thomas, Eunice Kennedy Shriver National Institute of Child Health and Human Development; Joshua P Rosenthal, Fogarty International Center; Conception R Nierras, NIH Office of Strategic Coordination Common Fund; and Katie Kavounis, Dong-Yun Kim, Antonello Punturieri, and Barry S Schmetter, NHLBI.

Conflicts of Interest: The authors declare no conflict of interest. 


\section{References}

1. GBD 2019 Risk Factors Collaborators. Global burden of 87 risk factors in 204 countries and territories, 1990-2019: A systematic analysis for the Global Burden of Disease Study 2019. Lancet 2020, 396, 1223-1249. [CrossRef]

2. Mortimer, K.; Ndamala, C.B.; Naunje, A.W.; Malava, J.; Katundu, C.; Weston, W.; Havens, D.; Pope, D.; Bruce, N.G.; Nyirenda, M.; et al. A cleaner burning biomass-fuelled cookstove intervention to prevent pneumonia in children under 5 years old in rural Malawi (the Cooking and Pneumonia Study): A cluster randomised controlled trial. Lancet 2017, 389, 167-175. [CrossRef]

3. Jack, D.W.; Ae-Ngibise, K.A.; Gould, C.F.; Boamah-Kaali, E.; Lee, A.G.; Mujtaba, M.N.; Chillrud, S.; Kaali, S.; Quinn, A.K.; Gyaase, S.; et al. A cluster randomised trial of cookstove interventions to improve infant health in Ghana. BMJ Glob. Health 2021, 6, e005599. [CrossRef] [PubMed]

4. Tielsch, J.M.; Katz, J.; Zeger, S.L.; Khatry, S.K.; Shrestha, L.; Breysse, P.; Checkley, W.; Mullany, L.C.; LeClerq, S.C. Designs of two randomized, community-based trials to assess the impact of alternative cookstove installation on respiratory illness among young children and reproductive outcomes in rural Nepal. BMC Public Health 2014, 14, 1271. [CrossRef]

5. Alexander, D.A.; Northcross, A.; Karrison, T.; Morhasson-Bello, O.; Wilson, N.; Atalabi, O.M.; Dutta, A.; Adu, D.; Ibigbami, T.; Olamijulo, J.; et al. Pregnancy outcomes and ethanol cook stove intervention: A randomized-controlled trial in Ibadan, Nigeria. Environ. Int. 2018, 111, 152-163. [CrossRef]

6. Checkley, W.; Williams, K.N.; Kephart, J.L.; Fandiño-Del-Rio, M.; Steenland, N.K.; Gonzales, G.F.; Naeher, L.P.; Harvey, S.A.; Moulton, L.H.; Davila-Roman, V.G.; et al. Effects of a Household Air Pollution Intervention with Liquefied Petroleum Gas on Cardiopulmonary Outcomes in Peru. A Randomized Controlled Trial. Am. J. Respir. Crit. Care Med. 2020, $203,1386-1397$. [CrossRef]

7. Dickinson, K.L.; Piedrahita, R.; Coffey, E.R.; Kanyomse, E.; Alirigia, R.; Molnar, T.; Hagar, Y.; Hannigan, M.P.; Oduro, A.R.; Wiedinmyer, $\mathrm{C}$. Adoption of improved biomass stoves and stove/fuel stacking in the REACCTING intervention study in Northern Ghana. Energy Policy 2019, 130, 361-374. [CrossRef]

8. Chillrud, S.N.; Ae-Ngibise, K.A.; Gould, C.F.; Owusu-Agyei, S.; Mujtaba, M.; Manu, G.; Burkart, K.; Kinney, P.L.; Quinn, A.; Jack, D.W.; et al. The effect of clean cooking interventions on mother and child personal exposure to air pollution: Results from the Ghana Randomized Air Pollution and Health Study (GRAPHS). J. Expo. Sci. Environ. Epidemiol. 2021, 31, 683-698. [CrossRef] [PubMed]

9. Carroll, C.; Patterson, M.; Wood, S.; Booth, A.; Rick, J.; Balain, S. A conceptual framework for implementation fidelity. Implement. Sci. 2007, 2, 40. [CrossRef] [PubMed]

10. Proctor, E.; Silmere, H.; Raghavan, R.; Hovmand, P.; Aarons, G.; Bunger, A.; Griffey, R.; Hensley, M. Outcomes for Implementation Research: Conceptual Distinctions, Measurement Challenges, and Research Agenda. Adm. Policy Ment. Health Serv. Res. 2011, 38, 65-76. [CrossRef] [PubMed]

11. Moore, G.F.; Audrey, S.; Barker, M.; Bond, L.; Bonell, C.; Hardeman, W.; Moore, L.; O'Cathain, A.; Tinati, T.; Wight, D.; et al. Process evaluation of complex interventions: Medical Research Council guidance. BMJ 2015, 350, h1258. [CrossRef]

12. Clasen, T.F.; Checkley, W.; Peel, J.L.; Balakrishnan, K.; McCracken, J.P.; Rosa, G.; Thompson, L.M.; Barr, D.B.; Clark, M.L.; Johnson, M.A.; et al. Design and Rationale of the HAPIN Study: A Multicountry Randomized Controlled Trial to Assess the Effect of Liquefied Petroleum Gas Stove and Continuous Fuel Distribution. Environ. Health Perspect. 2020, 128, 047008. [CrossRef]

13. Johnson, M.A.; Chiang, R.A. Quantitative Guidance for Stove Usage and Performance to Achieve Health and Environmental Targets. Environ. Health Perspect. 2015, 123, 820-826. [CrossRef]

14. Williams, K.N.; Thompson, L.M.; Sakas, Z.; Hengstermann, M.; Quinn, A.; Díaz-Artiga, A.; Thangavel, G.; Puzzolo, E.; Rosa, G.; Balakrishnan, K.; et al. Designing a comprehensive behaviour change intervention to promote and monitor exclusive use of liquefied petroleum gas stoves for the Household Air Pollution Intervention Network (HAPIN) trial. BMJ Open 2020, 10 , e037761. [CrossRef] [PubMed]

15. Johnson, M.A.; Steenland, K.; Piedrahita, R.; Clark, M.L.; Pillarisetti, A.; Balakrishnan, K.; Peel, J.L.; Naeher, L.P.; Liao, J.; Wilson, D.; et al. Air Pollutant Exposure and Stove Use Assessment Methods for the Household Air Pollution Intervention Network (HAPIN) Trial. Environ. Health Perspect. 2020, 128, 047009. [CrossRef]

16. Barr, D.B.; Puttaswamy, N.; Jaacks, L.M.; Steenland, K.; Rajkumar, S.; Gupton, S.; Ryan, P.B.; Balakrishnan, K.; Peel, J.L.; Checkley, W.; et al. Design and Rationale of the Biomarker Center of the Household Air Pollution Intervention Network (HAPIN) Trial. Environ. Health Perspect. 2020, 128, 047010. [CrossRef] [PubMed]

17. Quinn, A.K.; Williams, K.; Thompson, L.M.; Rosa, G.; Díaz-Artiga, A.; Thangavel, G.; Balakrishnan, K.; Miranda, J.J.; Rosenthal, J.P.; Clasen, T.F.; et al. Compensating control participants when the intervention is of significant value: Experience in Guatemala, India, Peru and Rwanda. BMJ Glob. Health 2019, 4, e001567. [CrossRef]

18. Hengstermann, M.; Díaz-Artiga, A.; Otzóy-Sucúc, R.; Ruiz-Aguilar, A.L.M.; Thompson, L.M.; Aravindalochanan, V.; Balakrishnan, K.; Barr, D.B.; Burrowes, V.; Campbell, D.; et al. Developing Visual Messages to Support Liquefied Petroleum Gas Use in Intervention Homes in the Household Air Pollution Intervention Network (HAPIN) Trial in Rural Guatemala. Health Educ. Behav. 2021, 48, 651-669. [CrossRef] [PubMed]

19. Wilson, D.L.; Williams, K.N.; Pillarisetti, A. An Integrated Sensor Data Logging, Survey, and Analytics Platform for Field Research and Its Application in HAPIN, a Multi-Center Household Energy Intervention Trial. Sustainability 2020, 12, 1805. [CrossRef] 
20. Harris, P.A.; Taylor, R.; Thielke, R.; Payne, J.; Gonzalez, N.; Conde, J.G. Research electronic data capture (REDCap)—A metadatadriven methodology and workflow process for providing translational research informatics support. J. Biomed. Infor. 2009, 42, 377-381. [CrossRef]

21. Simkovich, S.M.; Thompson, L.M.; Clark, M.L.; Balakrishnan, K.; Bussalleu, A.; Checkley, W.; Clasen, T.; Davila-Roman, V.G.; Diaz-Artiga, A.; Rosa, G.; et al. A risk assessment tool for resumption of research activities during the COVID-19 pandemic for field trials in low resource settings. BMC Med. Res. Methodol. 2021, 21, 68. [CrossRef] [PubMed]

22. Romieu, I.; Riojas-Rodríguez, H.; Marrón-Mares, A.T.; Schilmann, A.; Perez-Padilla, R.; Masera, O. Improved biomass stove intervention in rural Mexico: Impact on the respiratory health of women. Am. J. Respir. Crit. Care Med. 2009, 180, 649-656. [CrossRef]

23. Hanna, R.; Duflo, E.; Greenstone, M. Up in Smoke: The Influence of Household Behavior on the Long-Run Impact of Improved Cooking Stoves. Am. Econ. J. Econ. Policy 2016, 8, 80-114. [CrossRef]

24. Kirby, M.A.; Nagel, C.L.; Rosa, G.; Zambrano, L.D.; Musafiri, S.; Ngirabega, J.D.D.; Thomas, E.A.; Clasen, T. Effects of a large-scale distribution of water filters and natural draft rocket-style cookstoves on diarrhea and acute respiratory infection: A cluster-randomized controlled trial in Western Province, Rwanda. PLoS Med. 2019, 16, e1002812. [CrossRef] [PubMed]

25. Katz, J.; Tielsch, J.M.; Khatry, S.K.; Shrestha, L.; Breysse, P.; Zeger, S.L.; Kozuki, N.; Checkley, W.; LeClerq, S.C.; Mullany, L.C. Impact of Improved Biomass and Liquid Petroleum Gas Stoves on Birth Outcomes in Rural Nepal: Results of 2 Randomized Trials. Glob. Health Sci. Pr. 2020, 8, 372-382. [CrossRef]

26. Pope, D.; Johnson, M.; Fleeman, N.; Jagoe, K.; Duarte, R.; Maden, M.; Ludolph, R.; Bruce, N.; Shupler, M.; Adair-Rohani, $\mathrm{H}$.; et al. Are cleaner cooking solutions clean enough? A systematic review and meta-analysis of particulate and carbon monoxide concentrations and exposures. Environ. Res. Lett. 2021, 16, 083002. [CrossRef]

27. Baquié, S.; Urpelainen, J. Access to modern fuels and satisfaction with cooking arrangements: Survey evidence from rural India. Energy Sustain. Dev. 2017, 38, 34-47. [CrossRef]

28. Asante, K.P.; Afari-Asiedu, S.; Abdulai, M.A.; Dalaba, M.; Carrión, D.; Dickinson, K.L.; Abeka, A.N.; Sarpong, K.; Jack, D.W. Ghana's rural liquefied petroleum gas program scale up: A case study. Energy Sustain. Dev. 2018, 46, 94-102. [CrossRef]

29. Ozoh, O.B.; Okwor, T.J.; Adetona, O.; Akinkugbe, A.O.; Amadi, C.E.; Esezobor, C.; Adeyeye, O.O.; Ojo, O.; Nwude, V.N.; Mortimer, K. Cooking Fuels in Lagos, Nigeria: Factors Associated with Household Choice of Kerosene or Liquefied Petroleum Gas (LPG). Int. J. Environ. Res. Public Health 2018, 15, 641. [CrossRef]

30. Thompson, L.M.; Hengstermann, M.; Weinstein, J.; Diaz-Artiga, A. Adoption of Liquefied Petroleum Gas Stoves in Guatemala: A Mixed-Methods Study. EcoHealth 2018, 15, 745-756. [CrossRef]

31. Pye, A.; Ronzi, S.; Ngahane, B.H.M.; Puzzolo, E.; Ashu, A.H.; Pope, D. Drivers of the Adoption and Exclusive Use of Clean Fuel for Cooking in Sub-Saharan Africa: Learnings and Policy Considerations from Cameroon. Int. J. Environ. Res. Public Health 2020, 17, 5874. [CrossRef] [PubMed]

32. Thoday, K.; Benjamin, P.; Gan, M.; Puzzolo, E. The Mega Conversion Program from kerosene to LPG in Indonesia: Lessons learned and recommendations for future clean cooking energy expansion. Energy Sustain. Dev. 2018, 46, 71-81. [CrossRef] [PubMed]

33. Gould, C.; Schlesinger, S.; Toasa, A.O.; Thurber, M.; Waters, W.F.; Graham, J.P.; Jack, D. Government policy, clean fuel access, and persistent fuel stacking in Ecuador. Energy Sustain. Dev. 2018, 46, 111-122. [CrossRef] [PubMed]

34. Astuti, S.P.; Day, R.; Emery, S.B. A successful fuel transition? Regulatory instruments, markets, and social acceptance in the adoption of modern LPG cooking devices in Indonesia. Energy Res. Soc. Sci. 2019, 58, 101248. [CrossRef]

35. Shankar, A.V.; Quinn, A.K.; Dickinson, K.L.; Williams, K.N.; Masera, O.; Charron, D.; Jack, D.; Hyman, J.; Pillarisetti, A.; Bailis, R.; et al. Everybody stacks: Lessons from household energy case studies to inform design principles for clean energy transitions. Energy Policy 2020, 141, 111468. [CrossRef]

36. Puzzolo, E.; Zerriffi, H.; Carter, E.; Clemens, H.; Stokes, H.; Jagger, P.; Rosenthal, J.; Petach, H. Supply Considerations for Scaling Up Clean Cooking Fuels for Household Energy in Low- and Middle-Income Countries. GeoHealth 2019, 3, 370-390. [CrossRef] [PubMed]

37. Steenland, K.; Pillarisetti, A.; Kirby, M.; Peel, J.; Clark, M.; Checkley, W.; Chang, H.H.; Clasen, T. Modeling the potential health benefits of lower household air pollution after a hypothetical liquified petroleum gas (LPG) cookstove intervention. Environ. Int. 2018, 111, 71-79. [CrossRef]

38. Puzzolo, E.; Pope, D.; Stanistreet, D.; Rehfuess, E.A.; Bruce, N.G. Clean fuels for resource-poor settings: A systematic review of barriers and enablers to adoption and sustained use. Environ. Res. 2016, 146, 218-234. [CrossRef] [PubMed]

39. Pollard, S.L.; Williams, K.N.; O’Brien, C.J.; Winiker, A.; Puzzolo, E.; Kephart, J.L.; Fandiño-Del-Rio, M.; Tarazona-Meza, C.; Grigsby, M.R.; Chiang, M.; et al. An evaluation of the Fondo de Inclusión Social Energético program to promote access to liquefied petroleum gas in Peru. Energy Sustain. Dev. 2018, 46, 82-93. [CrossRef]

40. Pillarisetti, A.; Jamison, D.T.; Smith, K.R. Household Energy Interventions and Health and Finances in Haryana, India: An Extended Cost-Effectiveness Analysis. In Injury Prevention and Environmental Health, 3rd ed.; Mock, C.N., Nugent, R., Kobusingye, O., Smith, K.R., Eds.; The International Bank for Reconstruction and Development/The World Bank: Washington, DC, USA, 2017; Chapter 12. Available online: https:/ / pubmed.ncbi.nlm.nih.gov/30212113/ (accessed on 23 November 2021). 